\title{
ADRENAL CORTICAL HYPOPLASIA IN SIBLINGS
}

\author{
BY \\ J. F. BOYD and A. M. MACDONALD \\ From the Departments of Pathology, The University, Western Infirmary and \\ Royal Hospital for Sick Children, Glasgow
}

(RECEIVED FOR PUBLICATION MARCH 31, 1960)

There have been two reports recently of adrenocortical insufficiency in infant siblings. Mitchell and Rhaney (1959) reported it in two brothers, the first dying at 53 days and showing hypoplasia of the adrenal glands as the only apparent cause of death. The brother was born three years later, and exhibited a similar clinical picture of vomiting, wasting and dehydration shortly after birth. Biochemical studies were attempted but it became necessary to treat the child with adreno-cortical hormones and with sodium chloride added to his feeds. The child has remained alive to date, and it is assumed that he also suffers from adreno-cortical hypoplasia. Shepard, Landing and Mason (1959) reported adreno-cortical deficiency in two sisters. The first was well until 10 months and then developed a typical clinical picture. She died at 30 months and autopsy showed very small adrenal glands. There was no evidence of tuberculosis. The sister of this case, one of non-identical twins, developed symptoms after her first birthday; the other twin is healthy. After investigation, cortisone therapy was started and has had to be maintained, with much improvement. Neither sister exhibited a craving for salt and therefore the cortical deficiency is selective. This condition need not necessarily manifest itself early in childhood. The first case of Briggs, Goodwin and Wilson (1951), a boy of 12 years, had been fond of salt since infancy and clinically showed well developed Addison's disease. Radiographs showed calcification of mesenteric lymph nodes, but none in the region of the adrenal glands. Treatment with 'eucortone' at first, and later with D.C.A. pellet implants, and with sodium chloride orally, has been effective, and he was well at the time when the article was published. This boy's brother, 17 years of age, developed a more acute illness with epigastric pain, vomiting, loss of weight and increased depth of skin pigmentation. Treatment was given as for an Addisonian crisis, but he died 72 hours after admission to hospital. Necropsy revealed small adrenal glands, and histological examination showed atrophy of the cortex of each. There was no evidence of tuberculosis. The thymus was large. Both parents were healthy and the authors suggested that a genetic factor may be involved as in thyrotoxicosis, diabetes mellitus and the Laurence-Moon-Biedl syndrome.

We report a further family showing adrenal hypoplasia. Both boys in this family died in the neonatal period and received minimal corrective treatment. Therefore, the histological appearances of their endocrine glands are unaffected by therapy.

\section{Case Reports}

In 1953, the mother became pregnant for the first time, but had a spontaneous miscarriage at $4 \frac{1}{2}$ months. The cases reported were the result of second and third pregnancies.

Case 1. This male infant was born in hospital on May 4, 1955, as a spontaneous vertex delivery at full term after a normal pregnancy. The birth weight was 7 lb. 12 oz. (3. $52 \mathrm{~kg}$.). 'Physiological' jaundice appeared for a few days. Before dismissal, there had been occasional vomiting after breast feeding, but the condition subsided. The baby was well for his first four days at home, and then his condition deteriorated, and he was admitted to the Royal Hospital for Sick Children, Glasgow, on May 17, 1955. On that day his motions were green and very loose.

He was dehydrated, with poor muscle tone, although he was $113 \%$ of his expected weight. Lumbar puncture gave a clear cerebrospinal fluid. Rectal swabs revealed no pathogenic organisms. Four days later his general condition was improved but he remained rather listless. On May 23, 1955, he collapsed suddenly with copious green vomitus. 'Eucortone' $0.5 \mathrm{ml}$. was given every four hours. Surgical opinion was sought, and at laparotomy a volvulus was found involving the caecum and ascending colon. This was reduced and an obstructing band was divided. $140 \mathrm{ml}$. of quarter-strength normal saline with $5 \%$ glucose was given intravenously over the next six hours. Oral fluids were started four hours postoperatively and 'eucortone' was stopped on the fifth postoperative day. His condition improved over seven postoperative days, but on the eighth day (June 1, 1955) he went off his feeds once more, became marasmic and he died on June 2, 1955, at 4 weeks of age.

At necropsy the child weighed $5 \mathrm{lb} .10 \mathrm{oz}$. $(2 \cdot 55 \mathrm{~kg}$.). 


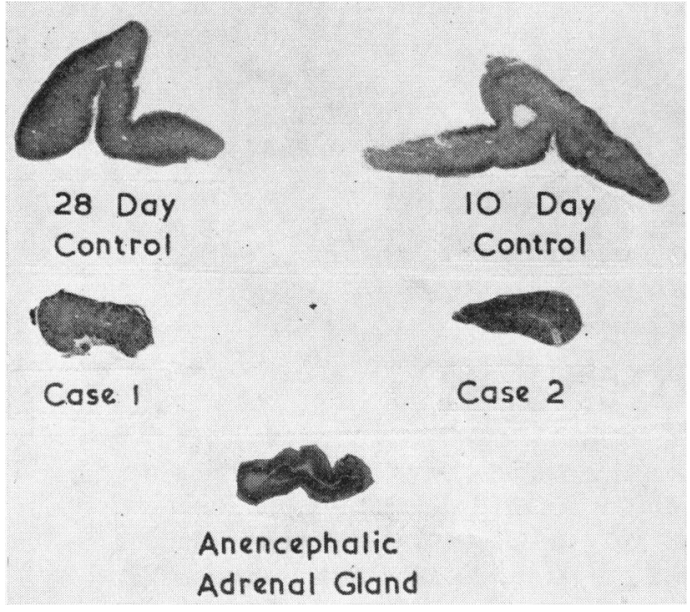

FIG. 1.-Specimens of adrenal glands of Cases 1 and 2 compared with normal controls for these ages and with an anencephalic adrenal gland. $(\times 5 / 3$. $)$

The abdominal surgical wound was healthy. The alimentary tract, liver (120 g.), pancreas and spleen (6 g.) were normal. The respiratory passages contained terminal bile-stained inhaled vomitus and the lungs showed mild patchy collapse. The heart $(17 \mathrm{~g}$.), great vessels, genito-urinary and central nervous systems were normal. The ductus arteriosus was widely patent. Both adrenal glands were exceedingly small (Fig. 1) and together they weighed $0.65 \mathrm{~g}$. No accessory adrenal tissue was found in the para-aortic area, pelvis or in relation to the testes which were fully descended.

The histological features will be considered later.

Case 2. In 1958 the mother became pregnant for the third time and suffered from no infection during this period; neither were radiographs taken. The child, a male, was born at home on October 7, 1958, and weighed $8 \mathrm{lb}$. (3.63 kg.). Progress was steady for a week, but on October 15, 1958, he vomited his feeds. On October 16 he refused his feeds and was cold, listless and grey. He continued to vomit and was admitted during the night to the Royal Hospital for Sick Children, Glasgow. His parents gave the history of a child who had died three years previously 'as a result of a twisted bowel'. Unfortunately, they were unaware of the additional condition found at necropsy, and in view of the urgency of treatment because of this present child's moribund condition, the clinicians involved did not consult the previous child's case records until later. In retrospect, this was perhaps unfortunate.

Examination, the child being 9 days old, showed him to be $95 \%$ of his expected weight, listless, grey, dehydrated and with a subnormal temperature. Lumbar puncture revealed a clear cerebrospinal fluid and the W.B.C. count was $10,800 / \mathrm{c} . \mathrm{mm}$. Blood was taken for culture, but only a contaminant grew. On the assumption that the child had an overwhelming infection, an intravenous infusion of quarter-strength normal saline with $5 \%$ glucose was set up. $100 \mathrm{mg}$. of hydrocortisone were placed in the contents of the first bottle. In addition, intramuscular hydrocortisone injections of $25 \mathrm{mg}$., and intramuscular tetracycline $25 \mathrm{mg}$. were given every six hours. The child died eight hours after admission.

At necropsy the child weighed $7 \mathrm{lb} .3 \mathrm{oz}$. (3.26 kg.). There was no abnormality of the respiratory passages, lungs, heart (29 g.), great vessels, the alimentary tract, liver (150 g.), pancreas, spleen (6 g.), the genito-urinary or central nervous systems. The only abnormality was the presence of unusually small adrenal glands. Together they weighed 0.9 g. (Fig. 1), and no adrenal tissue was found at any other site.

There was no family history of adrenal cortical hypofunction either in the grandparents, the parents or in their sibs.

Histological Features. The histological details of the two cases are similar and are considered together.

Adrenal Glands. Sudanophilic material is present in the zona reticularis of the adult cortex and in individual cells of the almost completely involuted foetal zone (Fig. 2). The features are the same in both cases, and are accompanied by cytomegaly in the foetal zone. The columns of the zona fasciculata are not normal for a resting gland (Fig. 3). Fig. 4 shows that there is barely any zona glomerulosa, and the cells of the zona fasciculata show much variability in size, and in nuclear and cytoplasmic staining properties. There is no evidence of the more insidious cytolytic necrosis seen in adult cases of Addison's disease (Crooke and Russell, 1935).

Professor T. Symington, Department of Pathology, Royal Infirmary, Glasgow, has examined one gland from each case by histological and by histochemical methods, and reports that both glands have been very active, and that he is unable to find any abnormality of function by these investigations.

Normal medullary tissue is present, but it is difficult to assess whether or not this is present in normal amount.

The Pituitary Gland. The glands were normally situated in both cases. Gomori's aldehyde-fuchsin method (Gomori, 1950) shows that basophil cells are present in increased numbers in both glands (Fig. 5). This finding has been confirmed by Lieb's phosphotungstic acid haematoxylin (Lieb, 1948), and modified trichrome and P.A.S. methods. Normally, basophils are present singly or in clumps of two or three cells. Fig. 5 shows marked hyperplasia in both cases, and, if anything, a tendency to become nodular in Case 1, which survived the longer.

Thus, adrenal hypoplasia is the primary defect and not the result of pituitary hypofunction in both of these children. Conclusive evidence is obtained from histological study of the other endocrine organs.

The Thyrom Gland. The thyroid gland in Case 2, who lived for 10 days, shows no abnormality (Fig. 6b). The gland of Case 1 who lived for four weeks, shows collapsed acini devoid of colloid (Fig. 6a), an appearance 


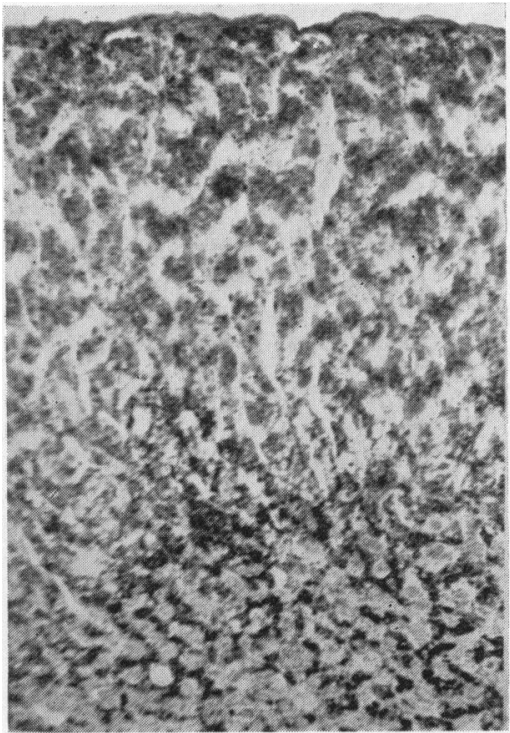

FIG. 2a.

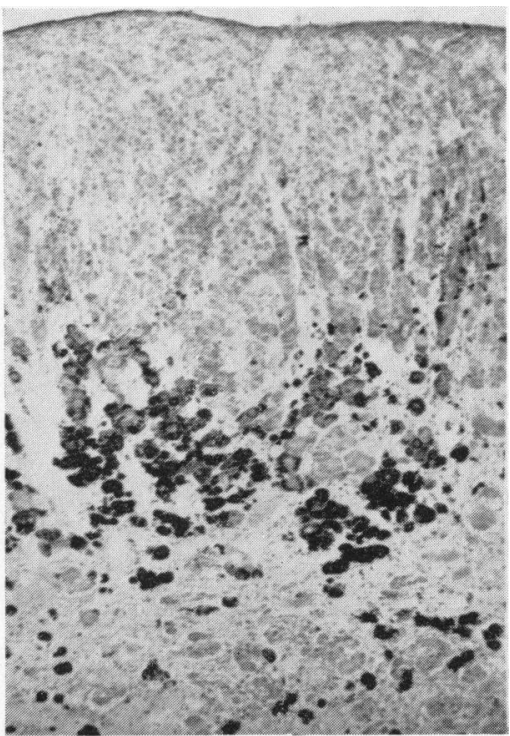

FIG. $2 b$.

Fug. 2.-Low power view of adrenal glands of Case 1, (a), and of Case 2, (b), stained with Sudan III and IV. The difference in quality of the two photographs is due to the gland of Case 1 being embedded in gelatin. $(\times 60$.

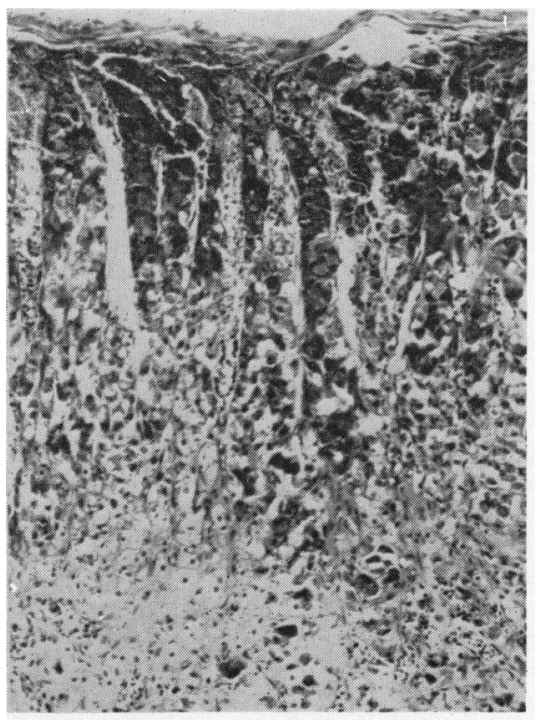

FIG. 3a.

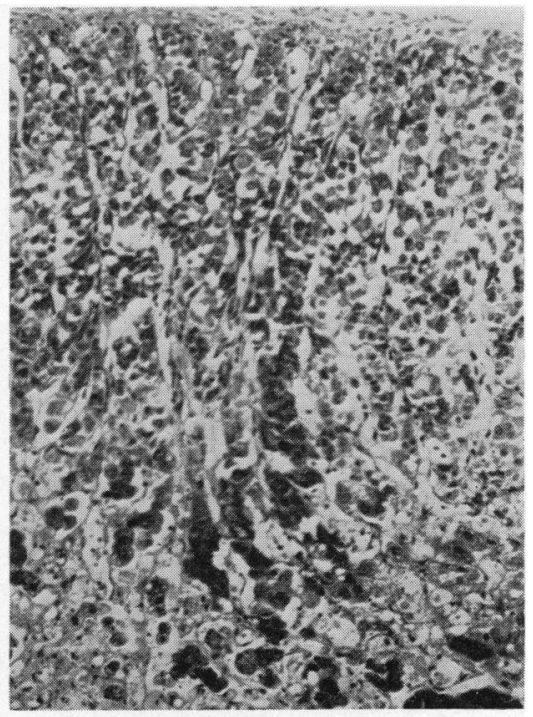

FIG. 3b.

Fig. 3.-Low power view of adrenal cortex of Case 1, (a), and of Case 2, (b), showing disorganization of cortical structure. (Masson's trichrome $\times 100$.) 


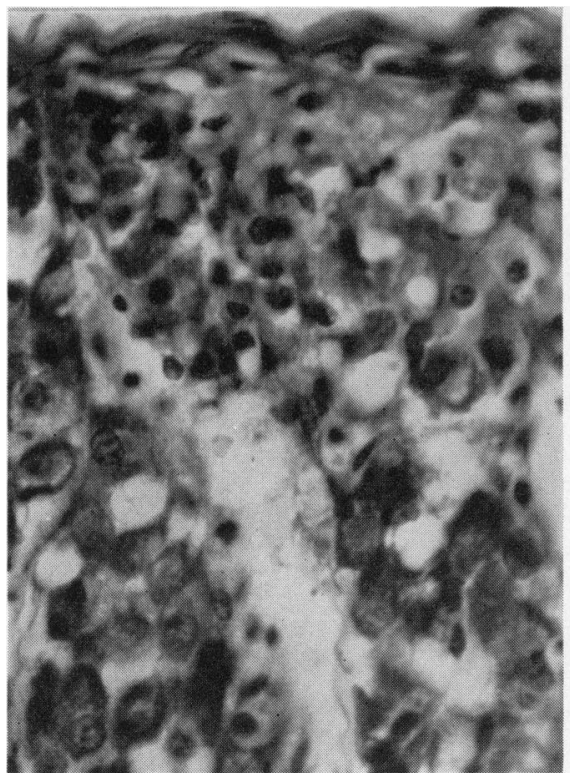

FIG. 4a.

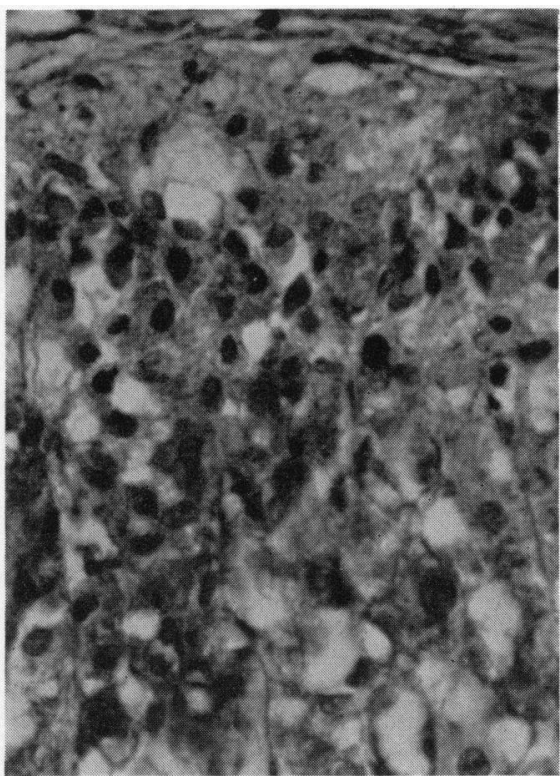

FIG. 4b.

Fig. 4.-High power view of adrenal cortex of Case 1, (a), and of Case 2, (b), showing poor zona glomerulosa and moderate pleomorphism of cells of zona fasciculata. (Masson's trichrome $\times 413$.)

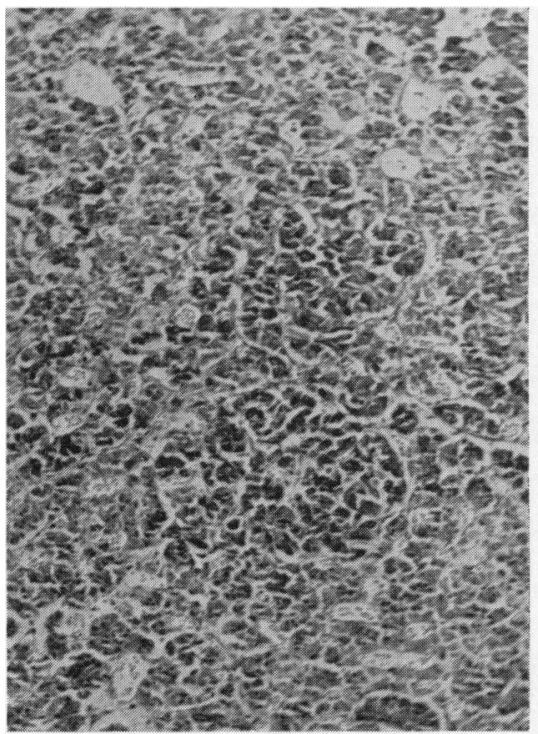

FIG. 5a.

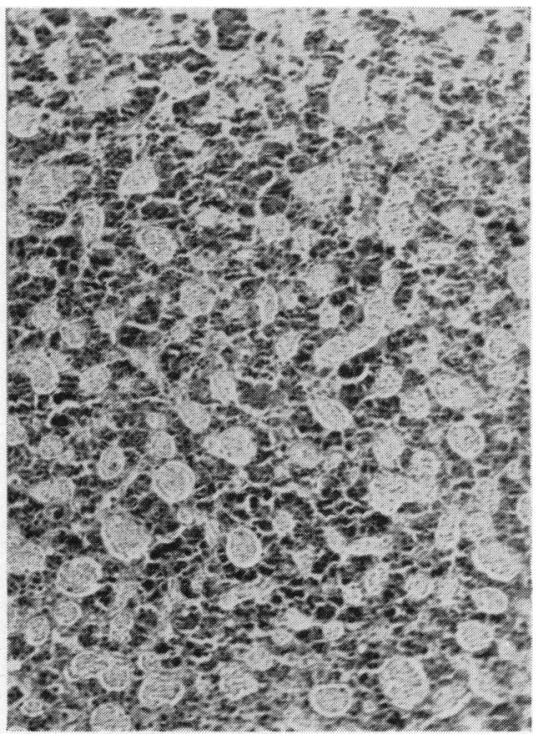

FIG. 5b.

Fig. 5.-Pituitary gland of Case 1, (a), and of Case 2, (b). The basophil cells are dark. (Gomori's aldehydefuchsin $\times 100$.) 


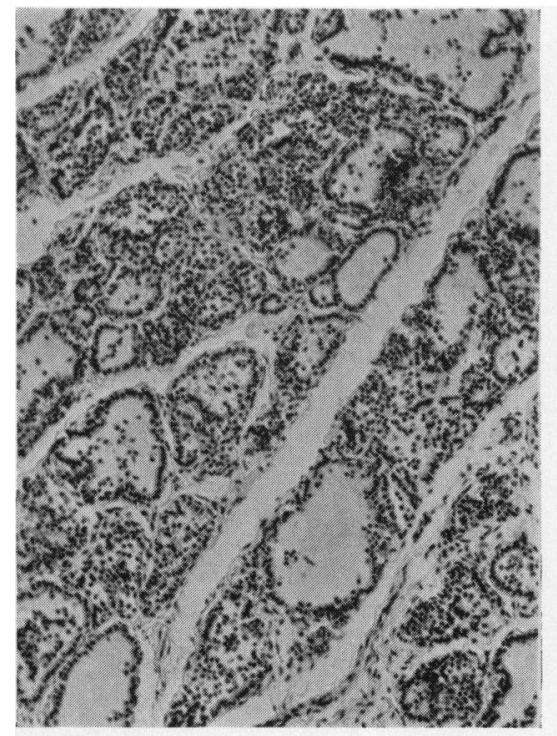

Fig, 6a.

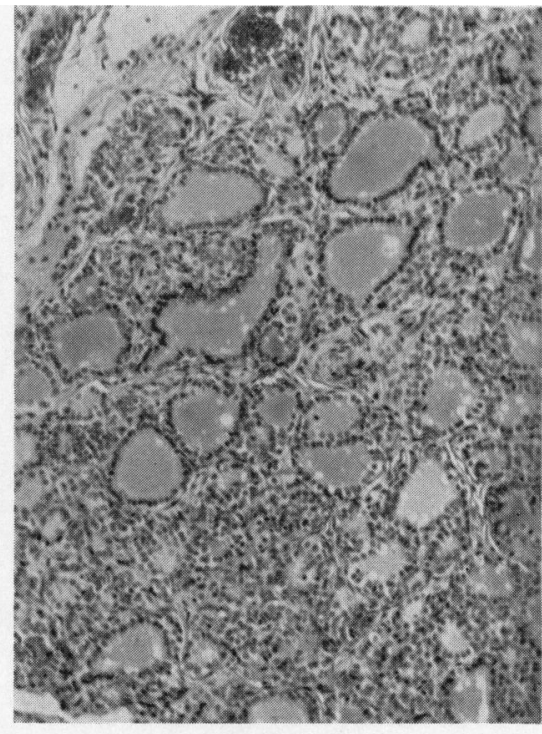

FIG. 6b.

Fig. 6.-Thyroid gland of Case 1, (a), and of Case 2, (b). The gland of Case 1 shows a thyrotrophic hormone-like effect. (Haematoxylin and Eosin $\times 100$.)

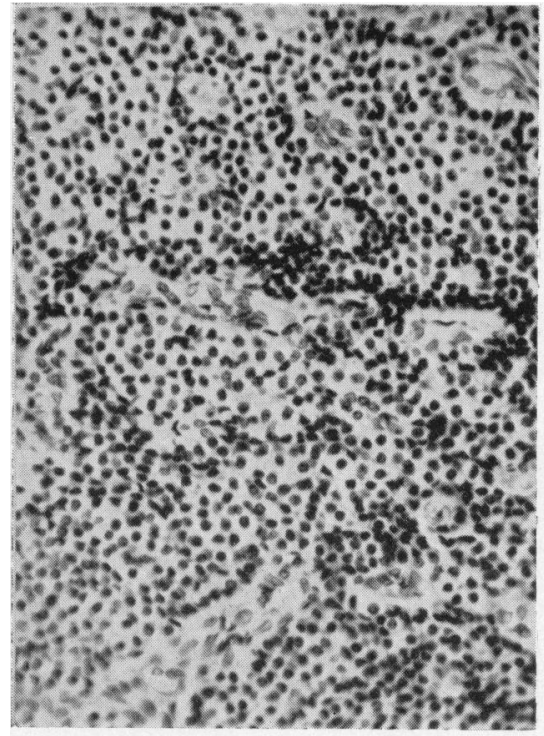

FIG. 7a.

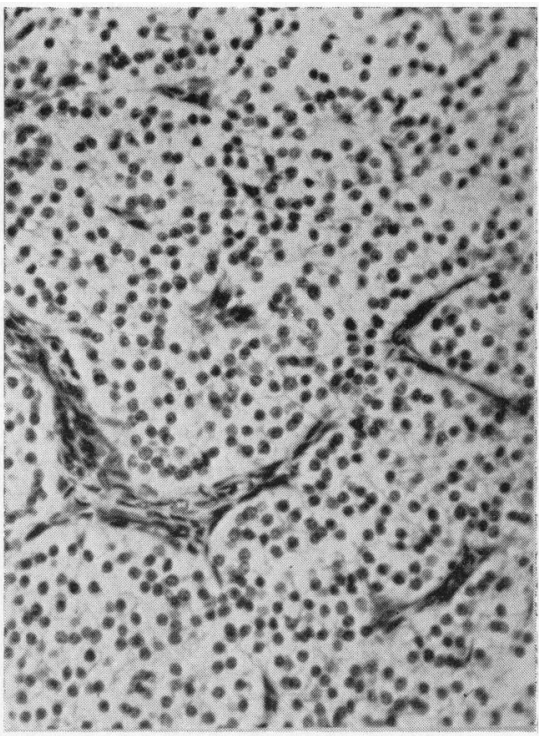

FIG. 7b.

Fig 7.-Parathyroid gland of Case 1, (a), and of Case 2, (b). The gland of Case 1 shows some upset which is difficult to interpret. (Haematoxylin and Eosin $\times 100$.) 


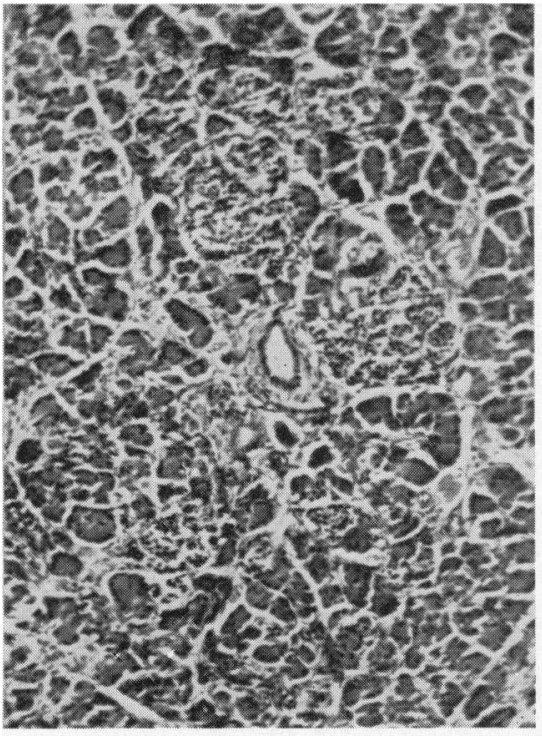

FIG. 8a,

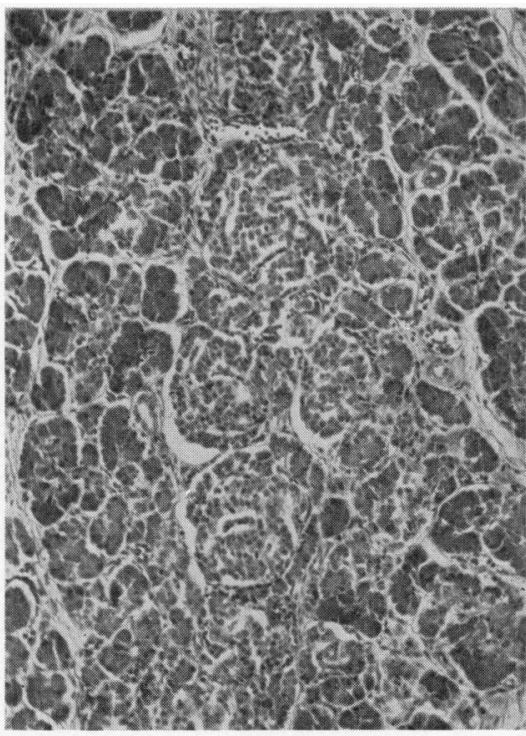

Fig. 8b.

FIG. 8.-Pancreas of Case 1, (a), and of Case 2, (b). Both are normal. (Haematoxylin and Eosin $\times$ 100.)

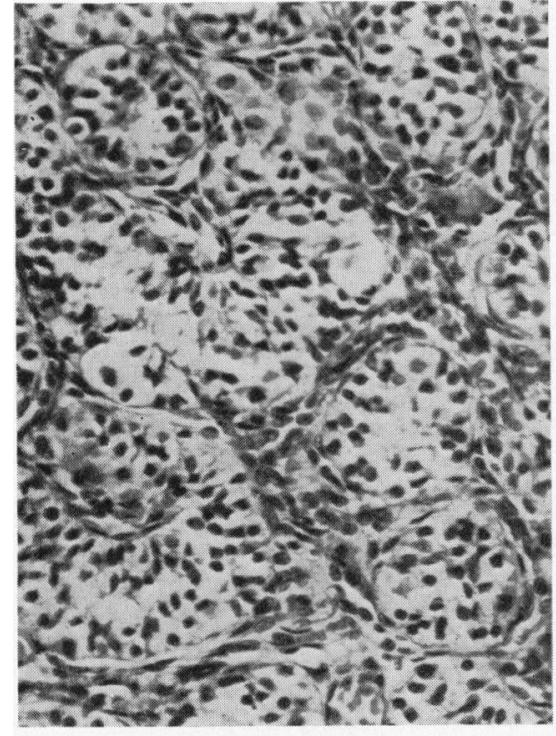

FIG. 9a.

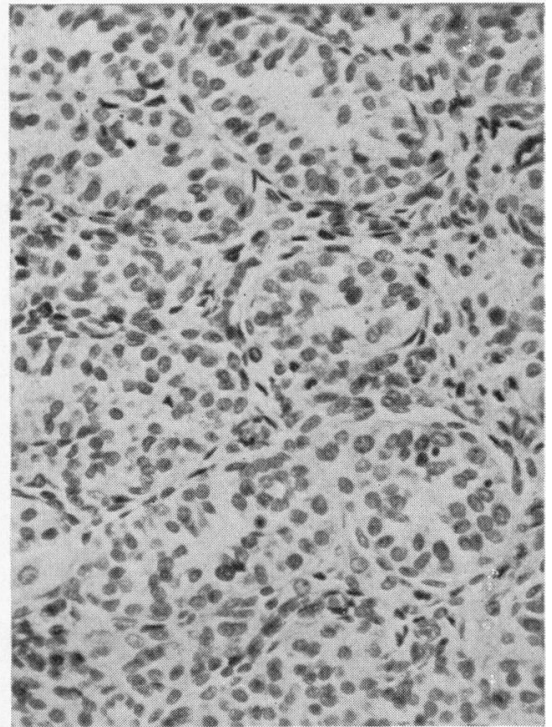

Fig. 9b.

Fig. 9.-Testis of Case 1, (a), and of Case 2, (b). The gland of Case 1 shows tubular atrophy with reduced spermatogenic activity. There is no detectable abnormality of the interstitial cells in either case. (Haematoxylin and Eosin $\times 100$.) 
which may result from over-production of thyrotrophic hormone (Sclare, 1956).

The Parathyroid Glands. In neither case do the glands appear to be unusually large or small. The gland of the shorter lived infant (Case 2) shows no histological abnormality (Fig. 7b). The gland of Case 1, however, shows an increased number of smaller cells with more hyperchromatic (or pyknotic) nuclei (Fig. 7a). We find it impossible to conclude from this whether the gland is undergoing atrophy or hyperplasia. In favour of atrophy is the apparent increase in condensation of blood vessels per field. On the other hand, Greene (1948) cites experimental evidence in favour of a parathyrotrophic hormone. Study of a section of rib from each case fails to demonstrate bone absorption, and a section of kidney from each case fails to show evidence of nephrocalcinosis by Von Kossa's stain. It may be that neither infant lived long enough to exhibit these changes.

The Islets of the Pancreas. Islet tissue appears to be present in normal amount (Fig. 8) and $\alpha$ and $\beta$ cells are present in both cases.

The Testis. The testis of Case 2 shows a normal degree of spermatogenesis (Fig. 9b). The testis of Case 1 shows a relative degree of atrophy of the seminiferous tubules (Fig. 9a) with markedly reduced spermatogenic activity, although artefact is present as a result of unsatisfactory fixation. This finding is consistent with the records of testicular atrophy in pituitary basophilism in the adult. Interstitial cells appear to be present in normal numbers in each case.

The Thymus. This organ is generally considered to be an endocrine gland, although in hypofunction of the adrenal cortex it appears to behave in the same manner as lymphoid tissue elsewhere in the body (Crooke and Russell, 1935). In the present two cases, the weight of the thymus was at the upper end of the scale of normal limits, and it must be assumed that the episode of adrenal hypofunction was too acute to allow time for the glands to show hyperplasia, regeneration or a reduced rate of involution.

\section{Discussion}

Hypoplasia of the adrenal glands is well known in association with anencephaly (Angevine, 1938) and in association occasionally with other congenital deformities of the central nervous system. In another group, however, adrenal hypoplasia is the only abnormality (Sikl, 1948; Deamer and Silver, 1950; Geppert, Spencer and Richmond, 1950; Provenzano, 1950; Welsh and Mehlin, 1954; Williams and Robinson, 1956; Harlem and Myhre, 1957; and MacMahon, Wagner and Weiner, 1957), and some of these cases have responded well to hormone therapy (e.g. Case 1 of Williams and Robinson, 1956). Some authors emphasized that the survival of these children was precarious, with sudden irrecoverable collapse if therapy were stopped even for a short period, and for this reason Mitchell and Rhaney (1959) felt that it was unjustified to investigate their second case fully while denying the infant the chance of recovery with replacement therapy. The histological appearances of the adrenal cortex of the brothers reported here resemble very closely those of Case 1 of Mitchell and Rhaney (1959) even to the presence of cytomegaly (Kampmeier, 1927; Beatty and Hawes, 1955). It should be stated that we are aware of endocrine gland involution during replacement therapy, but that we do not consider this process to be important in our cases, nor in the similar cases reviewed by us, because the adrenal glands are hyperactive. We believe that their small size is a congenital anomaly. It is essential in such cases, however, to make a thorough study of the whole endocrine system.

For example, Blizzard and Alberts (1956), Brewer (1957) and Ehrlich (1957) have described congenital aplasia or hypoplasia of the pituitary gland, and Mosier (1956) has recorded the condition, which is accompanied by hypoplasia of the adrenal glands, in siblings.

Further, our study of the literature reveals several familial syndromes which involve adrenal gland hypofunction: (1) The syndrome of hypoparathyroidism, adreno-cortical insufficiency and chronic moniliasis brought to general notice by Sutphin, Albright and McCune (1943) and followed by several reports, all from America (Leonard, 1946; Collins-Williams, 1950; Leifer and Hollander, 1953; Baker, 1954; Papadatos and Klein, 1954; Craig, Schiff and Boone, 1955; Whitaker, Landing, Esselborn and Williams, 1956; and DiGeorge and Paschkis, 1957); (2) the association of Addison's disease with thyroid gland changes in some instances (Wells, 1930; Anderson, Goudie, Gray and Timbury, 1957), and the well-known familial tendency to hyperthyroidism (Martin and Fisher, 1945), or to hypothyroidism as in sporadic non-endemic goitrous cretinism (Hutchison and McGirr, 1956), make a study of the thyroid gland essential; (3) the coincidence of diabetes mellitus and Addison's disease was described by Bloomfield (1939) and by McNicol and McNicol (1960) and since a familial tendency in diabetes is now well known, a familial tendency to both conditions simultaneously may be reported in the future; and (4) the syndrome of Addison's disease in association with familial spastic paraplegia has been recorded recently by Harris-Jones and Nixon (1955).

The existence of these conditions makes it necessary to examine not only these endocrine organs, but to examine the gonads histologically 
in order to exclude the presence of ectopic adrenal tissue at this site, and also to examine the central nervous system, mainly to exclude a congenital abnormality of the fore-brain. We were unaware of the existence of the association between Addison's disease and familial spastic paraplegia and therefore a histological examination of the spinal cord was not made.

The findings suggest that our cases exhibit primary adrenal gland hypoplasia with secondary pituitary basophilism, although it is not possible to state categorically that the infants would not have developed later one or other of the syndromes referred to above, had they survived.

\section{Summary}

Congenital adrenal hypoplasia is recorded in two brothers who died in the neonatal period.

Two previous examples of this condition in infants have been reported; one sibling has been maintained alive by replacement therapy in each.

Histological study suggests that the present two cases suffered from primary adrenal gland hypoplasia with secondary pituitary basophilism, the effects of which are demonstrable on the other endocrine glands.

We are very grateful to Dr. J. H. Hutchison for permission to abstract the case records of these two cases, to Professor S. Graham for advice, and to Professor T. Symington for studying an adrenal gland from each case.

\section{REFERENCES}

Anderson, J. R., Goudie, R. B., Gray, K. G. and Timbury. G. C (1957). Auto-antibodies in Addison's disease. Lancet. 1, 1123. Angevine, D. M. (1938). Pathologic anatomy of hypophysis and adrenals in anencephaly. Arch. Path. (Chicago), 26, 507.

Baker, W. H. (1954). Case records of the Massachusetts Genera Hospital (Case No. 40361). New Engl. J. Med., 251, 442.

Beatty, E. C. and Hawes, C. R. (1955). Cytomegaly of the adrenal gland. A.M.A. Amer. J. Dis. Child. 89,463 .

Blizzard, R. M. and Alberts, M. (1956). Hypopituitarism, hypoadrenalism and hypogonadism in the newborn infant. J. Pediat. 48, 782.

Bloomfield, A.. L. (1939). The coincidence of diabetes mellitus and Addison's disease. Effect of cortical extract on glycemia and glycosuria. Bull. Johns Hopk. Hosp. $65,456$.

Brewer, D. B. (1957). Congenital absence of the pituitary gland and its consequences. J. Path. Bact., 73, 59.

Briggs, J. N., Goodwin, J. F. and Wilson, A. (1951). Addison's disease occurring in two brothers. Brit. med.J. 1115.
Collins-Williams, C. (1950). Idiopathic hypoparathyroidism with papilledema in a boy six years of age. Pediatrics, 5, 998 .

Craig, J. M., Schiff, L. H. and Boone, J. E. (1955). Chronic moniliasi associated with Addison's disease. A.M.A. Amer. J. Dis. Child., 89, 669.

Crooke, A. C. and Russell, D. S. (1935). The pituitary gland in Addison's disease. J. Path. Bact. 40, 255.

Deamer, W. C. and Silver, H. K. (1950). Abnormalities in the secretion of the adrenal cortex during early life. J. Pediat., $37,490$.

DiGeorge, A. M. and Paschkis, K. (1957). The syndrome of Addison's disease, hypoparathyroidism, and superficial moniliasis. A.M.A. Amer. J. Dis. Child., 94, 476.

Ehrlich, R. M. (1957). Ectopic and hypoplastic pituitary with adrenal hypoplasia. J. Pediat., 51, 377.

Geppert, L. J., Spencer, W. A. and Richmond, A. M. (1950). Adrenal insufficiency in infancy. Ibid., 37, 1.

Gomori, G. (1950). Aldehyde-fuchsin: a new stain for elastic tissue. Amer. J. clin. Path., 20, 665.

Greene, R. (1948). The Practice of Endocrinology. 'The Practitioner Series.' Eyre and Spottiswoode, London.

Harlem, O. K. and Myhre, E. (1957). Congenital adrenal hypoplasia. A.M.A. J. Dis. Child., 94, 696.

Harris-Jones, J. N. and Nixon, P. G. F. (1955). Familial Addison's disease with spastic paraplegia. J. clin. Endocr., 15, 739.

Hutchison, J. H. and McGirr, E. M. (1956). Sporadic non-endemic goitrous cretinism. Lancet, 1, 1035.

Kampmeier, O. F. (1927). Giant epithelial cells of the human fetal adrenal. Anat. Rec., 37, 95.

Leifer, E. and Hollander, W. Jr. (1953). Idiopathic hypoparathyroidism and chronic adrenal insufficiency; $A$ case report. J. clin. Eindocr., 13, 1264.

Leonard, M. F. (1946). Chronic idiopathic hypoparathyroidism with superimposed Addison's disease in a child. Ibid., 6, 493.

Lieb, E. (1948). Modified phosphotungstic acid-hematoxylin stain. Arch. Path. (Chicago), 45, 559.

MacMahon, H. E., Wagner, R. and Weiner, D. B. (1957). Acute adrenal insufficiency due to congenital defect. A.M.A. J. Dis. Child., 94, 282.

McNicol, G. P. and McNichol, M. W. (1960). Addison's disease complicated by diabetes mellitus. Report of a case. Scot. med. J., 5,30 .

Martin, L. and Fisher, R. A. (1945). The hereditary and familial aspects of exophthalmic goitre and nodular goitre. Quart. J. Med., n.s. 14, 207.

Mitchell, R.' G. and Rhaney, K. (1959). Congenital adrenal hypoplasia in siblings. Lancet, $1,488$.

Mosier, H. D. (1956). Hypoplasia of the pituitary and adrenal cortex. Report of occurrence in twin siblings and autopsy cortex. Report of occurrence

Papadatos, C. and Klein, R. (1954). Addison's disease in a boy with hypoparathyroidism. J. clin. Endocr., 14, 653 .

Provenzano, R. W. (1950). Adrenocortical hypoplasia in the newborn infant. New Engl. J. Med., 242, 87

Sclare, G. (1956). The histological structure of the thyroid in the newborn. Scot. med. J., 1, 251.

Shepard, T. H., Landing, B. H. and Mason, D. G. (1959). Familial Addison's disease. A.M.A. J. Dis. Child., 97, 154.

Šikl, H. (1948). Addison's disease due to congenital hypoplasia of the adrenals in an infant aged 33 days. J. Path. Bact. $60,323$.

Sutphin, A. Albright, F and McCune, D. J. (1943). Five cases (three in siblings) of idiopathic hypoparathyroidism associated with moniliasis. J. clin. Endocr., 3, 625 .

Wells, H. G. (1930). Addison's disease with selective destruction o the suprarenal cortex. Arch. Path. (Chicago), 10, 499.

Welsh, J. B. and Mehlin, G. B. (1954). Congenital adrenal aplasia. A.M.A. Amer. J. Dis. Child., 87, 319.

Whitaker, J., Landing, B. H., Esselborn, V. M. and Williams, R. R. (1956). The syndrome of familial juvenile hypo-adrenocorticism hypoparathyroidism and superficial moniliasis. J. clin. Endocr., 16, 1374 .

Williams, A. and Robinson, M. J. (1956). Addison's disease in infancy. Arch. Dis. Childh. 31265 